\title{
STUDENTS' CLIP THINKING: A PROBLEM APPROACH
}

\author{
Irina Bakhmetieva ${ }^{1 *}$, Vladimir Gorbunov ${ }^{2}$, Mikhail Burov ${ }^{3}$, Omari Margalitadze ${ }^{4}$, Elena \\ Vostroilova ${ }^{5}$ \\ ${ }^{1}$ Associate Professor, Voronezh State Pedagogical University, RUSSIA, irbakh@mail.ru \\ ${ }^{2}$ Associate Professor, the State University of Land Use Planning, RUSSIA, \\ vsgorbunov@yahoo.com \\ ${ }^{3}$ Professor, the State University of Land Use Planning, RUSSIA, m.burov-m.burov@yandex.ru \\ ${ }^{4}$ Associate Professor, the State University of Land Use Planning, RUSSIA, m-on-42@mail.ru \\ ${ }^{5}$ Associate Professor, Voronezh State Pedagogical University, RUSSIA, elenavostroilova@mail.ru \\ ${ }^{*}$ Corresponding Author
}

\begin{abstract}
Purpose: The aim of the paper is to discuss the phenomenon of students' clip thinking, its roots and ways of handling the problem in a higher education establishment. The research reflects concerns of domestic and foreign scholars and educational professionals about the students having the mosaic worldview devoid of logical reasoning rather than the integral picture of the world.

Methodology: The methodological basis of the study is the data of the general and special scientific methodology. Dialectics has determined the reasoning. The philosophical principle of the universal connection of objects and phenomena of objective reality, the principle of determinism and systematicity are taken as a basis as well.

Result: The research has sparked the students' interest in the problem of clip thinking under study, the reasons for its occurrence, and ways to handle it. Although most students have a clear idea of the term "clip thinking", and, therefore, succeed in analysing the reasons for its development, few of them are able to practise what they intuitively (and correctly) regard as appropriate. As seen from the research, all the students involved in the experiment need a closer communication with the university professors and a greater engagement in the academic and extra-curricular activities in order to develop integral thinking, imagination, memory, oratorical skills and many others essential for future professionals.
\end{abstract}

Application: The research can be useful to university and school professionals, scholars and students.

Keywords: clip thinking, students, integral worldview, university, mosaic thinking, education professional

\section{INTRODUCTION}

The urgency of students' clip thinking problem is related to profound understanding of the essence of this phenomenon, to domestic and foreign scientists' and practice-oriented teachers' concerns about the lack of a holistic picture of the world in the students' minds. In modern scholarship clip thinking (fragmentary, mosaic, collage, kaleidoscopic) is paid due attention to. It is defined as the process of reflecting numerous diverse properties of objects in a person's mind, without taking into account any connections between them, so the world picture that individuals have is mostly based on the fragmentation of incoming information, and is characterised by illogical character, complete heterogeneity of the incoming stream and a high speed of switching pieces of information (Semenovskikh, 2014, p. 5). 
As it is known, the term "clip culture" was first mentioned in A. Toffler's "The Third Wave: The Classic Study of Tomorrow" as a phenomenon typical of the information society, in which clip thinking becomes the main perception means, since contemplating about synthesis in this connection seems an inconsistent idea. Thus, the easiest way to explore and percept the world is to randomly organize its objects. Toffler regards clip culture as a logical consequence of the information influx, which is characteristic of the society postindustrial phase (Toffler, 1984). This special type of thinking, clip consciousness, appeared under the influence of IT, which, thanks to the media and aggressive Internet marketing, continues to spread at an alarming rate. The number of "clip thinking" individuals is quickly increasing as well and is currently approaching the critical point, after which irreversible changes are brought about in other people's minds and society as a whole (Volkodav, Semenovskikh, 2017, pp. 345-353).

At educational establishments clip thinking students may have difficulty doing elementary scientific research and drawing simple logical conclusions. For instance, to organize their presentations, they tend to poach ideas, look for the logical connections that they may find in similar researches, and skip the most important information. With mosaic thinking, individuals are prone to false pluralism in processing the same text, which leads educational professionals to believe that such students are motivationally deficient.

What ultimately distinguishes previous generations from the present one, according to $\mathrm{V}$. Kolobaev and $\mathrm{K}$. Vorobyeva, is obtaining information in a "linear way", the process in which perception, memorization and reproduction of information are sequential and are links in the same chain. In the previous years students tended to analyze and synthesize the material thus forming a holistic worldview, whereas the modern generation of students does not perceive this information in succession but in separate clips that bear no logical connection to each other (Kolobaev, 2019). Next, social psychologist S. Turkle in "Alone Together: Why We Expect More from Technology and Less from Each Other," claims that the communication culture we have created and an over-reliance on digital technologies can also result in feelings of loneliness, anxiety and emotional disconnection (Turkle, 2011).

In this connection, the aim of the study is to get an insight into the phenomenon of the students' clip thinking, the reasons, as well as the ways of addressing the issue.

\section{METHODOLOGY}

The methodological basis of the study is the data of the general and special scientific methodology. Dialectics has determined the reasoning. The philosophical principle of the universal connection of objects and phenomena of objective reality, the principle of determinism and systematicity are taken as a basis as well.

The studies are based on conceptual ideas regarding the clip thinking of such scientists as: I. P. Berezovskaya, V. M. Bukatov, F. I. Girenok, H.M. McLuhan, N. A. Romanov, T. S. Slivin, A. Toffler, A. A. Fasolya, K. G. Frumkin, etc.

Within the framework of the specific scientific methodology, research methods of pedagogical reality were used, including analysis, rethinking of well-known concepts when presenting their content; the idea of a Ushaped curve in scientific research; principles and methods for forecasting new solutions; analysis of scientific literature; terminological matrix method.

The second and third-year students of the Faculty of Foreign Languages, Voronezh State Pedagogical University, who are prospective teachers, were asked three questions in order to find out their attitude to the problem of clip thinking:

1. What is clip thinking in your understanding?

2. What are the causes of students' clip thinking?

3. What are the ways to handle students' clip thinking?

\section{RESULTS}

The third-year students answered the first question as follows: a person's idea of other countries imposed by the media - $35 \%$ of the respondents; the ability to perceive the world through short vivid images, clips - $34 \%$; superficial thinking - 24\%; inability to form their thoughts, to focus on one issue for a long time - $7 \%$.

The second-year students presented their answers to Question 1 in a more varied way: perception of the world through short vivid images, not holistically, superficially - 51\%; the perception of the world as a set of disparate facts - 25\%; when a person does not think about the process, the actions are automatic, quick, only basic information is perceived - $14 \%$; reaction to rapidly changing conditions $-3.4 \%$; poor preparation 
for the lesson - 3.3\%; describing the way of perceiving information - 3.3\%.

So, the students' idea of clip thinking is diverse and relies on their personal judgement regarding this phenomenon. More than half of the students $(65 \%$ of the total number) in the third year understand correctly the meaning of the term, while the remaining $35 \%$ of the respondents associate this phenomenon with a person's idea of other countries, which may be explained by the fact that they major in foreign languages and think it appropriate to associate any phenomenon, even if not delving into the essence, with a foreign language culture. Among second- year students, $96.7 \%$ of the total number of the respondents have an idea of clip thinking and give a partly correct definition, which characterises only some aspects of the concept under study. $3.3 \%$ of the students identify clip thinking as poor preparation for classes, since they themselves are probably truants.

Table 1. The third-year students' responses to Question 1

\begin{tabular}{|c|l|c|}
\hline № & \multicolumn{1}{|c|}{ Characteristic } & $\%$ \\
\hline $\mathbf{1}$ & an idea of other countries imposed by the media & 35 \\
\hline $\mathbf{2}$ & the ability to perceive the world through short vivid images & 34 \\
\hline $\mathbf{3}$ & superficial thinking & 24 \\
\hline $\mathbf{4}$ & inability to form their thoughts, to focus on one issue for a long time & 7 \\
\hline & Total & 100 \\
\hline
\end{tabular}

Table 2. The second-year students' responses to Question 1

\begin{tabular}{|c|l|c|}
\hline $\mathbf{N}$ & \multicolumn{1}{|c|}{ Characteristic } & $\%$ \\
\hline $\mathbf{1}$ & an idea of other countries imposed by the media & 35 \\
\hline $\mathbf{2}$ & the ability to perceive the world through short vivid images & 34 \\
\hline $\mathbf{3}$ & superficial thinking & 24 \\
\hline $\mathbf{4}$ & inability to form their thoughts, to focus on one issue for a long time & 7 \\
\hline & Total & 100 \\
\hline
\end{tabular}

As for Question 2, the following reasons for the emergence of clip thinking were named by the third-year prospective teachers: active introduction of the Internet with its short articles, videos, and social networks $33.5 \%$ of the respondents; an increasing role in nanotechnology and ICT in human life - 33\%; inability to concentrate on information for a long time; reduced ability to analyze information - 9\%; complete immersion in studies or work and access to the Internet, which offers "prête- à -porter" solutions to any home assignment $-9 \%$. A quick look at the material, only superficial facts draw attention, only keywords are highlighted - $8 \%$; lack of independence $-7.5 \%$.

In the second year, the majority of the respondents (68\%) see a great flow of information as the main reason for students' clip thinking; excessive use of phones, laptops, tablets, Internet resources - $17 \%$ of the respondents; development of modern technologies, the acceleration of the rhythm of life, reading little 8.7\%; communication with an incompetent teacher $(0.1 \%)$; the students have no perseverance; a large amount of educational material; the students do not want or cannot express their thoughts, write essays, learn poetry by heart $-4.1 \%$; multitasking, vanity $-2.1 \%$.

After analyzing the answers it becomes clear that the respondents of both the third and second years see one of the main reasons for the emergence of the students' clip thinking in the active introduction of the Internet, the huge speed of the information flow, the excessive use of phones, laptops, tablets and ICTs (in the $3 r d$ year $-66.5 \%$ of the total number of the respondents, in the 2 nd year $-85 \%$ of the total number of the 
respondents). As a consequence of the aforementioned, the representatives of both years point to the inability to concentrate on information for a long time, inability to analyze, laziness, lack of perseverance, difficulty in expressing their thoughts, fear of writing essays, unwillingness to memorize verses and lack of independence. One person pointed out among the reasons for the emergence of the students' clip thinking communication with an incompetent teacher. This answer is probably related to a specific episode in the student's life.

Table 3. The third-year students' responses to Question 2

\begin{tabular}{|c|l|c|}
\hline № & \multicolumn{1}{|c|}{ Characteristic } & \multicolumn{1}{|c|}{$\%$} \\
\hline $\mathbf{1}$ & active introduction of the Internet with its short articles, videos, and social networks & 33.5 \\
\hline $\mathbf{2}$ & an increasing role in nanotechnology and ICT in human life & 33 \\
\hline $\mathbf{3}$ & $\begin{array}{l}\text { inability to concentrate on information for a long time; reduced ability to analyze } \\
\text { information }\end{array}$ & 9 \\
\hline $\mathbf{4}$ & $\begin{array}{l}\text { complete immersion in studies or work and access to the Internet, which offers "prête- à } \\
\text {-porter" solutions to any home assignment }\end{array}$ & 9 \\
\hline $\mathbf{5}$ & $\begin{array}{l}\text { a quick look at the material; only superficial facts draw attention; only keywords are } \\
\text { highlighted }\end{array}$ & 8 \\
\hline $\mathbf{6}$ & lack of independence & 7.5 \\
\hline & Total & 100 \\
\hline
\end{tabular}

Table 4. The second-year students' responses to Question 2

\begin{tabular}{|c|l|c|}
\hline № & \multicolumn{1}{|c|}{ Characteristic } & \multicolumn{1}{|c|}{$\%$} \\
\hline $\mathbf{1}$ & a great flow of information & 68 \\
\hline $\mathbf{2}$ & excessive use of phones, laptops, tablets, Internet resources & 17 \\
\hline $\mathbf{3}$ & development of modern technologies, the acceleration of the rhythm of life, reading little & 8.7 \\
\hline $\mathbf{4}$ & communication with an incompetent teacher & 0.1 \\
\hline $\mathbf{5}$ & $\begin{array}{l}\text { no perseverance; a large amount of educational material; the students do not want or } \\
\text { cannot express their thoughts, write essays, learn poetry by heart }\end{array}$ & 4.1 \\
\hline & multitasking, vanity & 2.1 \\
\hline & Total & 100 \\
\hline
\end{tabular}

The third -year students' answers to Question 3 regarding the ways of overcoming clip thinking among students are as follows: reduce the use of the media, teach students critical thinking $-53.5 \%$ of the respondents; read more fiction, relax more, do sports - $20.4 \%$; perform creative tasks that require expressing the students' opinion, a detailed retelling of what was read $-17.3 \%$, the students' maximum involvement in the discipline, understandable explanation $-4.4 \%$; closer communication between the teachers and the students $-4.4 \%$.

The second-year students, among the ways to handle clip thinking, mention the following: reading fiction and philosophical literature with a subsequent analysis of what they read, developing holistic thinking, imagination, training memory, conducting discussions $-69.1 \%$ of the respondents; availability of a day's rest 
from information; to devote time to leisure $-16.2 \%$; less homework; interest in the discipline $-6,4 \%$; meditation; time management $-5.9 \%$; harmony with oneself, classmates and nature $-2.4 \%$.

Table 5. The third-year students' responses to Question 3

\begin{tabular}{|c|l|c|}
\hline № & \multicolumn{1}{|c|}{ Characteristic } & \multicolumn{1}{|c|}{$\%$} \\
\hline 1 & reduce the use of the media, teach students critical thinking & 53.5 \\
\hline 2 & read more fiction, relax more, play sports & 20.4 \\
\hline 3 & $\begin{array}{l}\text { perform creative tasks that require expressing the students' opinion, a detailed } \\
\text { retelling of what was read }\end{array}$ & 17.3 \\
\hline 4 & $\begin{array}{l}\text { the students' maximum involvement in the discipline, teachers' understandable } \\
\text { explanation }\end{array}$ & 4.4 \\
\hline 5 & closer communication between the teachers and the students & 100 \\
\hline & Total & 4.4 \\
\hline
\end{tabular}

Table 6. The second-year students' responses to Question 3

\begin{tabular}{|c|l|c|}
\hline № & \multicolumn{1}{|c|}{ Characteristic } & $\%$ \\
\hline 1 & $\begin{array}{l}\text { reading fiction and philosophical literature with a subsequent analysis of what is read, } \\
\text { developing holistic thinking, imagination, training memory, conducting discussions }\end{array}$ & 69.1 \\
\hline 2 & availability of a day's rest from information; to devote time to leisure & 16.2 \\
\hline 3 & less homework; interest in the discipline & 6.4 \\
\hline 4 & meditation; time management & 5.9 \\
\hline 5 & harmony with oneself, classmates and nature & 2.4 \\
\hline & Total & 100 \\
\hline
\end{tabular}

\section{CONCLUSION}

The research has sparked the students' interest in the problem of clip thinking under study, the reasons for its occurrence, and ways to handle it. The study demonstrates that although most students have a clear idea of the term "clip thinking", and, therefore, succeed in analysing the reasons for its development, few of them are able to practise what they intuitively (and correctly) regard as appropriate.

As seen from the research, all the students involved in the experiment need a closer communication with the university professors and a greater engagement in the academic and extra-curricular activities in order to develop integral thinking, imagination, memory, oratorical skills and many others essential for future professionals.

\section{REFERENCE LIST}

Semenovskikh, T. (2014). The phenomenon of «clip-thinking» in the educational high school environment. Internet journal "Naukovedenie", vol. 5 (24).

Toffler, A. (1984). The Third Wave: The Classic Study of Tomorrow.

Volkodav T., Semenovskikh T. (2017). Dichotomy of the 'clip thinking' phenomenon. Proceedings of ICEPS 
2017 (International Conference on Education, Psychology, and Social Sciences). vol. 4.

Kolobaev V.K., Vorobyeva K.V. (2019). Clip thinking and teaching foreign languages in non-linguistic higher education institutions: psychological and pedagogical aspects. International research journal. Vol. 9(87) https://doi.org/10.23670//RJ.2019.87.9.027

Turkle S. (2011) Alone Together: Why we expect more from technology and less from each other. 